Invited Editorial

\title{
Samantha Adams Festschrift: Sam Adams and the Social Construction of Technology and Health-Implications for Biomedical Informatics
}

\author{
Laurie L. Novak ${ }^{1}$ Craig Kuziemsky ${ }^{2}$ Bonnie Kaplan ${ }^{3}$ \\ ${ }^{1}$ Department of Biomedical Informatics, Vanderbilt University \\ Medical Center, Nashville, Tennessee, United States \\ 2 Telfer School of Management, University of Ottawa, Ottawa, \\ Ontario, Canada \\ 3 Yale University, New Haven, Connecticut, United States \\ Appl Clin Inform 2018;9:496-499.
}

\section{Background}

Clinical informatics, as an applied subdiscipline of biomedical informatics (BMI), must expertly use concepts from BMI core disciplines to design and deploy technologies to improve human health. The core disciplines include, among others, computer science, medicine, and social science. Applying social science concepts is perhaps the most challenging because issues related to people and organizations often have many interpretations, explanations, and solutions. Sam Adams, a social scientist who enjoyed engaging the most complex theoretical domains, made valuable contributions to thorny social problems at the intersection of technology and people. In this article, we argue that her work and the theoretical topics she chose for emphasis should be more widely consumed by practitioners in clinical informatics. As an example, we focus on social constructionism, one general theoretical topic she favored. Sam used social constructionism to explore domains relevant to today's practicing clinical informaticist, including cybersecurity and social media.

\section{Social Constructionism}

"Social construction" and the related term "co-construction" refer both to a large body of scholarship and to a particular way of viewing knowledge systems and technologies. ${ }^{1}$ The basic premise is that systems of knowledge (for example, biomedicine, or more specifically genetics) and technologies of all sorts reflect the worldview of their designers and users. Further, it is argued that influential knowledge systems and technologies are the continually evolving products of a social process of design. For example, the International Classification of

Diseases is a knowledge system that cannot be traced back to an individual designer; instead, it is the evolving product of negotiations and strategies of a variety of interest groups. ${ }^{2}$

Sociotechnical theory, as used in BMI, is social constructionist. Sociotechnical theory posits that social and technological systems continually shape each other, a process of coconstruction. It is necessarily an interdisciplinary approach. ${ }^{3}$

\section{Cybersecurity}

Sam advocated for a sociotechnical agenda to address cybersecurity. Sociotechnical theory is interdisciplinary and employs multiple methods of analysis, both of which were among her strengths. She understood that different disciplines' theories and methods offered important insights into complex problems such as cybersecurity. In 2015, she led a comparative review project of cybersecurity governance in five countries commissioned by the Dutch Ministry of Security and Justice. ${ }^{4}$ The report they produced focused on how cloud (and other) service providers can be accountable for how they manage personal, sensitive, and confidential information. ${ }^{5}$ It took an interdisciplinary approach to analyzing accountability and how to achieve it. It drew not only on standard methods for social and economic accountability assessment but also on the technology acceptance model developed in the information systems field by Davis, ${ }^{6}$ and on acceptance of technologies and the Diffusion of Innovations (DoI) Model, developed originally in Communications by Rogers. ${ }^{7}$ As they put it,

Understanding the interplay between these and other factors requires an interdisciplinary approach to understanding acceptance (e.g., value for money, market segmentation,

(c) 2018 Georg Thieme Verlag KG Stuttgart · New York
DOI https://doi.org/ 10.1055/s-0038-1656524. ISSN 1869-0327.

Laurie L. Novak, PhD, MHSA,

Department of Biomedical

Informatics, Vanderbilt University

Medical Center, 2525 West End

Avenue Suite 1475, Nashville,

TN 37203, United States

(e-mail: laurie.I.novak@vanderbilt.

edu). 
etc.) of given technologies in specific settings. The SEIA [socio-economic impact assessment] conducted here, supplemented by aspects from theories regarding DoI and technology acceptance, provides insights regarding factors contributing to or detracting from acceptance of accountability measures in cloud ecosystems. ${ }^{5}$

"Using insights from these models," they wrote, "reveals three key concepts that shape social and economic accountability: trust, control and transparency." ${ }^{5}$ These concepts influenced the scenarios they developed, the interviews and questionnaires they administered, their security threat analysis, the accountability development tool they proposed, and their policy recommendations. Not only was this a novel combination of theories, it was a novel combination of methods, all informed by the conviction that interdisciplinarity was needed to address the problem of cloud security as a technological as well as people and organizational issue. They commented on the relationship between an organization's code of ethics and the degree of organizational and IT architectural restructuring needed for demonstrable accountability (p. 36).

Moreover, they saw it as both an ethical and legal issue as well as a social, technological, and organizational one. Their fictional scenarios "try to anticipate ethical, legal and social dynamics, [which] are also an important part of a SEIA because they help researchers anticipate the likely acceptance of a given accountability tool, explore the dynamics of interaction between current morality and new technologies, and outline relevant governing mechanisms," and the tool they developed (p. 5) "educates the user on risks and threats to ensure the ethical aspects of accountability (p. 22)."

This interdisciplinary thrust also is evident when considering security and privacy in health care. In Adams and Petersen, ${ }^{8}$ for example, the authors brought in the sociological criticism of increasing medicalization of both society and cyberspace, as well as the observation that the definition of "disease" is shifting. Further, drawing on Foucault's well-known analysis of surveillance, she and colleagues brought together surveillance studies scholars who are expanding Foucault's ideas together with eHealth scholars in a conference to inspire crossfertilizing these two previously unrelated streams of scholarship. ${ }^{9}$ Their contributions included insights from legal, ethical, social, and surveillance studies for cybersecurity in eHealth. Sam recognized that as information technologies (ITs) have infused health care and spread out into society at large through mobile health applications, individuals and groups may feel much more under observation in ways that lead to ethical, legal, and social issues often lost in the excitement over what these technologies can do. The resulting volume, therefore, contains chapters on a range of these issues from scholars in a variety of disciplines.

Sam's chapter ${ }^{10}$ revisits Foucault and expands the discussion beyond Discipline and Punish ${ }^{11}$ to consider The Birth of the Clinic, ${ }^{12}$ his work on "the clinic" and "medical gaze." Instead of Foucault's analysis of forms of knowledge and spatial configuration, or emphasis on how technologies increase surveillance, she poses the theoretical question of how changing structures and technologies change what the "clinic" is, and proposes further research on the increasingly common status of individual citizens as patients (i.e., "patientism") by medical professionals, and power relations between them. ${ }^{10}$

In doing so, Sam exhibits not only her command of different disciplinary approaches and theories, but also her bent toward co-construction, or the ways in which different actors and perspectives interact to co-produce new structures, meanings, and behaviors. She plays disciplines off each other to build new ideas, both theoretical and methodological. The interplay of methods, of theories, and of methods together with theories, leads to knowledge creation, as in her call for bringing together five separate arenas of study related to cybersecurity, privacy, and the protection of (health) data: (1) cybersecurity studies, which examine the sociopolitical and technical governance of critical infrastructures and mitigation of threats to systems such as botnets; (2) patient safety, which examines concrete sociotechnical and organizational challenges related to the protection of large-scale health information technology (HIT) systems; (3) surveillance studies; (4) studies in bioethics, which each examine different aspects of (potential) threats to personal privacy through networked technologies; and (5) legal studies, which examine (proposed) changes to the laws and regulations that govern data creation and exchange. ${ }^{4}$

Bringing these disciplines together to address cybersecurity in health care would necessarily change how each addresses cybersecurity, thereby co-constructing "cybersecurity" as well as each discipline, which, in turn continues the cycle of changing ideas of cybersecurity and how to achieve it. This integrative thinking is evident in how she sees organizational, ethical, and legal issues related to cybersecurity as a package rather than as separate areas. It is not surprising that Sam was active in the American Medical Informatics Association's (AMIA) Working Groups on Ethical, Legal, and Social Issues (ELSI) and on People and Organizational Issues (POI). In her perspective, ELSI and POI are interacting, interrelated issues, each of which affect each other in a continuing interplay in which all the issues are co-constructed by each other, the technologies, the people, the organizations, the legal environment, and the like. As she points out: "digital technologies, public policy, medical services and daily life continue to fold into one another in various, sometimes unexpected, ways." Together they change ideas of health care delivery, what being a patient means and involves, relationships between patients and clinicians, health behaviors, ideas of privacy, what constitutes illness, changes in power relationships related to health care technologies and surveillance, and a host of other important areas. ${ }^{10}$

\section{Social Media}

Public access to Web 2.0 applications and social media tools such as weblogs, microblogs, wikis, media/file sharing sites, and networking sites have digitized society and enabled a democratization of knowledge by empowering citizens to contribute to its production. Sam considered this shift to a participatory society particularly important in health care, which has historically been defined by a clear knowledge 
hierarchy of expertise with classic forms of evidence (e.g., randomized controlled trials) considered the only valid knowledge to guide medical practices. ${ }^{13}$ Nonprofessionals (e.g., individuals with no form of medical training) are now able to contribute their own experiential evidence to provide an alternative account of reality to challenge the dominant knowledge hierarchy of existing medical evidence. Sam saw individual patients using social media to produce experiential information that can be co-constructed with other patient experiences to create a richer body of evidence for the collective benefit of other patients, health care professionals, policymakers, and commercial organizations. ${ }^{13}$ Sam's case example of crowdsourcing to enable co-production of knowledge about pharmaceutical experiences describes how crowdsourcing applications shift the balance of power by acting as a "broker" to enable experiential knowledge drawn from individual experiences to complement existing sources of traditional pharmaceutical evidence. ${ }^{13}$

However, many unanswered questions remain about how the co-construction of knowledge between multiple people and/or organizations works. Sam asks how Web 2.0 tools challenge, reinforce, and complement existing knowledge sources. Her work shows that social media tools act as a mediator between patients and other health system agents (e.g., people or institutions) by collecting information about individual experiences and repackaging this information to create experiential evidence about day-to-day health care practice. ${ }^{14}$ In understanding the co-construction process, Sam adopts the perspective of others ${ }^{15,16}$ in inferring that mediation from social media tools is not neutral but rather it transforms and translates information as part of the co-construction of knowledge. She extends existing work by focusing on the manner in which the mediation role influences the nature and structure of information exchange during the process of co-construction at both micro and macro levels. At a micro level, she explores the role of crowdsourcing for knowledge creation of patient experiences with pharmaceuticals and of eCoaches on individual behaviors. ${ }^{13,17}$ Sam states that it is still unknown exactly how patient experiences are used for co-construction of pharmaceutical knowledge, noting that at times patient experiences are edited or excluded during the processes of information mediation. ${ }^{13}$ She also contributes to the consumer health informatics field by showing that eCoaches can enable co-construction of behavioral changes to support healthy lifestyle changes, but she notes, too, that they can pose risks to individual users' autonomy if people simply rely on the eCoach for reflection on behavior and selection of goals rather than co-constructing them. ${ }^{17}$ At a macro level, Sam explains that while social media platforms enable gathering, disseminating, and exchanging healthrelated information between hospitals and patients, there is still much to learn about how care institutions and broader health authorities use social media for patient engagement. ${ }^{18}$

\section{Conclusion}

Sam makes an important distinction between co-construction in theory and how it is actually done in practice by showing that technology used to facilitate co-construction is not neutral but rather plays an active role in co-construction of knowledge. She affirms that co-construction is more than simply creating common knowledge but is in fact a complex interdisciplinary endeavor. Our examples of Sam's work highlight a need to better understand the process of co-construction, and how people, processes, and technology interact during co-construction. Power or health literacy differentials can create divisions in health care consumers' participation in the democratization of health-related knowledge. The contributions of researchers and health IT designers will be enriched if they are informed by an analysis of the power asymmetries that are being perpetuated by computational tools. Sam's work complements others in emphasizing the need to draw upon social science disciplines to better understand how co-construction occurs and evolves over time. Incorporating participatory approaches ${ }^{19,20}$ and social science methods $s^{21,22}$ in the design and evaluation of BMI tools and applications, as Sam did for cybersecurity and for social media, would help us understand how informatics tools are socially constructed, how that affects their use and effectiveness, and how we can make this process more deliberate.

One of Sam's important contributions was the linkage of people and organizational issues with ethical and legal issues. This may seem an obvious connection, but we too often pay little attention to how individual, organizational, and societal responses to technological issues produce many of our ethical dilemmas, and how the interplay of the social and technological present different views of ethical and legal issues. Studying how ethical dilemmas are produced by people and organizations, and then reckoned with by people and organizations, will produce key insights for informatics in the coming decade, preparing the discipline for participation in important societal conversations. Sam's dedication to advancing society's thinking related to ethical, legal, and social issues was evidenced in her active involvement in the related AMIA Working Groups. She participated in the analysis and writing for a 2015 paper that examined thousands of comments on an influential AMIA listserv. ${ }^{23}$ Over several years, she served as both chair and co-chair of the Diana Forsythe Award Committee. She facilitated as the group reckoned with the expanding scope of the Award's domain: the intersection of social sciences and technology. Sam represented innovative areas of research, particularly the area of digital ethnography, and its inclusion in the Award's domain is the result of her advocacy.

In this article, we illustrate how Sam's attention to theoretical issues produced insights directly applicable to clinical informatics. They led to better understanding of how people use social networking in health care and how cybersecurity can be improved. Sam's penchant for learning from and contributing to other disciplines is evident in her work. As her cybersecurity analysis shows, it enabled recommendations for improving HITs, their use, and policies governing them. We encourage working informaticists to become familiar with the language and concepts that underlie science and technology studies and related theories. ${ }^{21,22,24,25}$ This integrative approach and knowledge of multiple theoretical and 
disciplinary approaches can improve one's awareness of the social implications of design features and choices, resulting in more enlightened informatics tools and research.

\section{Acknowledgment}

The authors gratefully acknowledge the work, insights, and unforgettable friendship of Samantha Adams.

\section{References}

1 Bijker WE, Hughes TP, Pinch T, et al. The Social Construction of Technological Systems: New Directions in the Sociology and History of Technology. Cambridge, Massachusetts: MIT Press; 2012

2 Bowker GC, Star SL. Sorting Things Out: Classification and Its Consequences. Cambridge, Massachusetts: MIT Press; 2000

3 Harrison MI, Koppel R, Bar-Lev S. Unintended consequences of information technologies in health care-an interactive sociotechnical analysis. J Am Med Inform Assoc 2007;14(05): 542-549

4 Aarts J, Adams S, Kaplan B, et al. Protecting Patient Privacy in Cyber Environments. Chicago: American Medical Informatics Association; 2016

5 Niezen M, van Woensel D, Nunez D, et al. D: A4. 1 Socio-economic impact assessment. TILT, Tilburg University; 2016

6 Davis FD. User acceptance of information technology: system characteristics, user perceptions and behavioural impacts. Int J Hum Comput Stud 1993;38:475-487

7 Rogers EM. Diffusion of Innovations. 4th ed. New York: The Free Press; 1995

8 Adams SA, Petersen C. Precision medicine: opportunities, possibilities, and challenges for patients and providers. J Am Med Inform Assoc 2016;23(04):787-790

9 Adams S, Purtova N, Leenes R. Under Observation: The Interplay Between eHealth and Surveillance. Springer; 2017

10 Adams S. Ubiquitous Digital Devices and Health: Reflections on Foucault's Notion of the "Clinic." In: Under Observation: The Interplay Between eHealth and Surveillance. Cham, Switzerland: Springer; 2017:165-176

11 Foucault M. Discipline and punish. Translated by A. Sheridan. New York: N Y Pantheon; 1977;139:1992
12 Foucault M. The Birth of the Clinic (translated by A.M. Sheridan). London: Tavistock; 1973

13 Adams SA. Maintaining the collision of accounts: crowdsourcing sites in health care as brokers in the co-production of pharmaceutical knowledge. Inf Commun Soc 2014;17:657-669

14 Adams SA. Sourcing the crowd for health services improvement: The reflexive patient and "share-your-experience" websites. Soc Sci Med 2011;72(07):1069-1076

15 Latour B. Reassembling the Social: An Introduction to ActorNetwork-Theory. Oxford: Oxford University Press; 2005

16 Wathen N, Wyatt S, Harris R. Mediating Health Information: The Go-Betweens in a Changing Socio-Technical Landscape. New York: Springer; 2008

17 Adams S, Niezen M. Digital "solutions" to unhealthy lifestyle "problems": the construction of social and personal risks in the development of eCoaches. Health Risk Soc 2016;17:530-546

18 Adams S. Use of Social Media by Hospitals and Health Authorities. In: Syed-Abdul S, Gabarron E, Lau AYS, eds., Participatory Health Through Social Media. London: Academic Press; 2016:27-41

19 Unertl KM, Schaefbauer CL, Campbell TR, Senteio C, Siek KA, Bakken S, Veinot TC. Integrating community-based participatory research and informatics approaches to improve the engagement and health of underserved populations. J Am Med Inform Assoc 2016;23(01):60-73

20 Kanstrup AM, Bygholm A, Bertelsen P. Participatory Design \& Health Information Technology. Amsterdam: IOS Press; 2017

21 Greenhalgh T, Stones R. Theorising big IT programmes in healthcare: strong structuration theory meets actor-network theory. Soc Sci Med 2010;70(09):1285-1294

22 Kaplan B. Evaluating informatics applications-some alternative approaches: theory, social interactionism, and call for methodological pluralism. Int J Med Inform 2001;64(01):39-56

23 Ravvaz K, Kuziemsky C, Koppel R, et al. AMIA members' “vital signs": what the HIT implementation listserv says about goals for AMIA and for medical informatics. American Medical Informatics Association; 2015:1067

24 Forsythe D. Studying Those Who Study Us: An Anthropologist in the World of Artificial Intelligence. Stanford, CA: Stanford University Press; 2001

25 Pratt W, Reddy MC, McDonald DW, Tarczy-Hornoch P, Gennari JH. Incorporating ideas from computer-supported cooperative work. J Biomed Inform 2004;37(02):128-137 